\title{
Comparison of survival of patients receiving laparoscopic and open radical resection for stage II colon cancer
}

\author{
Cui-Zhen Fan ${ }^{1}$, Yu-Ping Chư ${ }^{1}$, Ping Wei², Hong Dai², Wenming Chen ${ }^{3}$ \\ ${ }^{1}$ Department of Oncology, Beijing Chaoyang Hospital, Capital University of Medical Science, Beijing, China \\ ${ }^{2}$ Department of Pathology, Beijing Chao yang Hospital, Capital University of Medical Science, Beijing, China \\ ${ }^{3}$ Department of Hematologic Neoplasms and Oncology, Beijing Chaoyang Hospital, Capital University of Medical Science, \\ Beijing, China
}

Received 28 March 2011

Accepted 10 July 2011

Correspondence to: Wenming Chen, Departement of Hematologic Neoplasms \& Oncology, Beijing Chaoyang Hospital, No.8 Baijazhuang Road Beijing 100020, China. Phone: +86 10 85231240; Fax: +86 10 85231244; Email: chenq52000@163.com

Disclosure: No potential conflicts of interest were disclosed.

Background. The aim of the study was to compare the survival of patients receiving laparoscopic vs. open radical resection for stage II colon cancer.

Patients and methods. Two hundred and twenty patients with stage II colon cancer were enrolled from Beijing Chaoyang Hospital of Capital Medical University from January 2000 to December 2009, including 61 patients in the laparoscopic radical resection group and 159 patients in the open radical resection group. The survival data in both groups were compared using the log rank test based on Kaplan-Meier survival curves.

Results. There was no statistically significant difference in the 3-year survival $\left(88.5 \%\right.$ vs. $\left.80.5 \% ; X^{2}=1.98, P=0.159\right)$ and the 5 -year survival $\left(81.9 \%\right.$ vs. $\left.69.2 \% ; X^{2}=1.98, P=0.159\right)$ between both groups. However, statistically significant difference was found in median overall survival (mOS), which was 102.6 (95\% Cl: 76.8-122.7) months in the laparoscopic group and 90.0 (95\% Cl: 70.4-109.6) months in the open radical resection group ( $\left.X^{2}=4.183, P=0.041\right)$. $\mathrm{mOS}$ was 96 (95\% Cl: 68.6-111.4) months and 92.6 (95\% Cl: 56.8-107.2) months in those with and without postoperative chemotherapy, respectively $\left(X^{2}=6.389, P=0.011\right)$. For patients older than 75 years the mOS was 90.0 (95\% Cl: 25.3-105.0) months and 83.4 (95\% Cl: 13.1-96.9) months in the laparoscopic and open group, respectively. The difference between the both groups was statistically significant $\left(X^{2}=6.191, P=0.013\right)$.

Conclusions. The mOS of patients receiving laparoscopic radical resection was better than open radical resection for stage II colon cancer, especially for patients over 75 years old.

Key words: stage II colon cancer; laparoscopy; chemotherapy; prognosis

\section{Introduction}

The incidence of colorectal cancer is 3.6-59.1 per 100,000 people worldwide. ${ }^{1}$ It is one of the most common malignancies in the world. Its incidence is still increasing as people's lifestyle changes; especially in developing countries. ${ }^{2,3}$ Surgical resection is still the only approach for curing colorectal cancer. The gold criterion of successful removal is that the cancer margins and lymph nodes in relative regions are completely resected. Currently there are many reports available on laparoscopic radical resection for colorectal cancer. Laparoscopic radical resection achieves rapid recovery and few postoperative complications with recognized short-term outcomes better than open radical resection. ${ }^{4-7}$ Latest follow-up data of laparoscopic radical resection also confirm the long-term outcomes of laparoscopic radical resection for colorectal cancer; the 1-year, 3-year, and 5-year survival following laparoscopic radical resection is similar to that following open radical resection..$^{5-7}$ However, the survival might depended on post-treatment surveillance of 


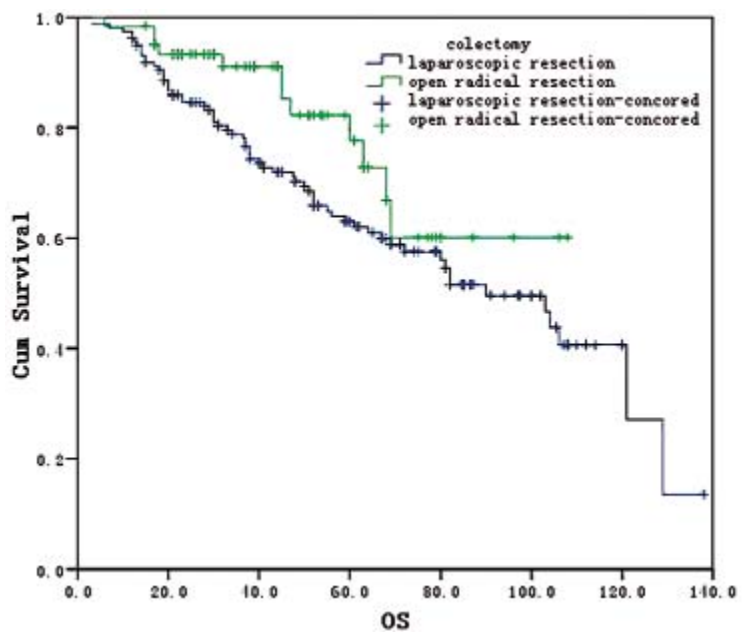

FIGURE 1. Overall survival curves for 220 patients undergoing laparoscopic and open radical resection.

patients. ${ }^{8}$ There is also report on better efficacy of laparoscopic radical resection than open radical resection as laparoscopic radical resection reduces cancer recurrence, cancer-related mortality and other risks. ${ }^{9}$ In the present study, the survival of patients receiving laparoscopic and open radical resection for stage II colon cancer in 220 patients with stage II colon cancer enrolled from Beijing Chaoyang Hospital of Capital Medical University between January 2000 and September 2009 were retrospectively compared.

\section{Patients and methods}

Two hundred and forty-nine patients with stage II colon cancer were treated in Beijing Chaoyang Hospital of Capital Medical University from January 2000 to December 2009. Twenty-nine patients were lost during the follow up. Two hundred and twenty of them were included into the present study according to the inclusion criteria. There were 61 in the laparoscopic radical resection group and 159 in the open radical resection group. The inclusion criteria were: (a) complete medical records with definitive pathology diagnosis of colon cancer treated with radical resection; (b) stage II in the TNM staging system and neoadjuvant chemotherapy not practiced. Exclusion criteria were: (a) synchronous or metachronous colorectal carcinoma, or familial adenomatous polyposis; (b) multiple primary malignant tumours; (c) surgery complication related death; and (d) laparoscopic radical resection replaced by open radical resection. Informed consent was obtained from all these

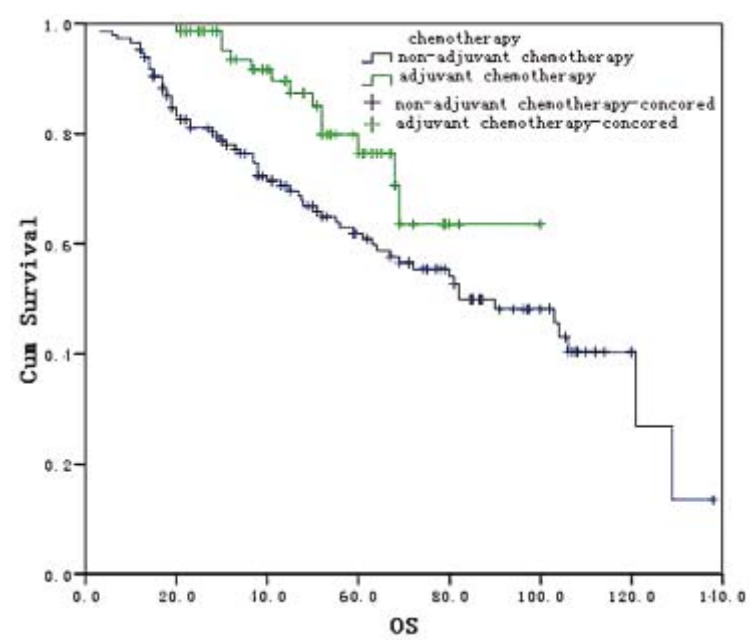

FIGURE 2. Overall survival curves for 220 patients with or without adjuvant chemotherapy.

patients. Sixty-four patients underwent postoperative 5-fluorouracil based chemotherapy, while 156 patients were only underwent radical resection.

Preparations prior to laparoscopic and open radical resection were similar. Tracheal catheterization and general anaesthesia were administered. Surgical procedure was performed according to instructions for tumour-free surgery.

Among 64 patients treated with chemotherapy, fifty-tree patients underwent 5 -fluorouracil based chemotherapy, complemented by calcium folinate, cis-platinum and oxaliplatin for 4-6 courses, and 11 patients were treated by xeloda alone or combination of xeloda and oxaliplatin for 6-8 courses.

Evaluation of recurrence of colon cancer comprised physical examination, chest X-ray, abdominal CT, and colonoscopy (once a year). The patients were followed up through telephone, outpatient visits and inpatient records. The follow up started from the day of surgery and ended on December 31, 2010. The end-point-data would be 3, 5-year survival and median overall survival (mOS).

Statistical analyses were done using SPSS 15.0. $\mathrm{X}^{2}$ test was performed for general data including age and gender. The Kaplan-Meier survival curves and the log rank test were used to analyse the survival data with the selection of operation and treatment. For all analyses, the level of significance was set at $P<0.05$.

\section{Results}

There was no statistically significant differences in the gender, age, cancer site, histological classifica- 


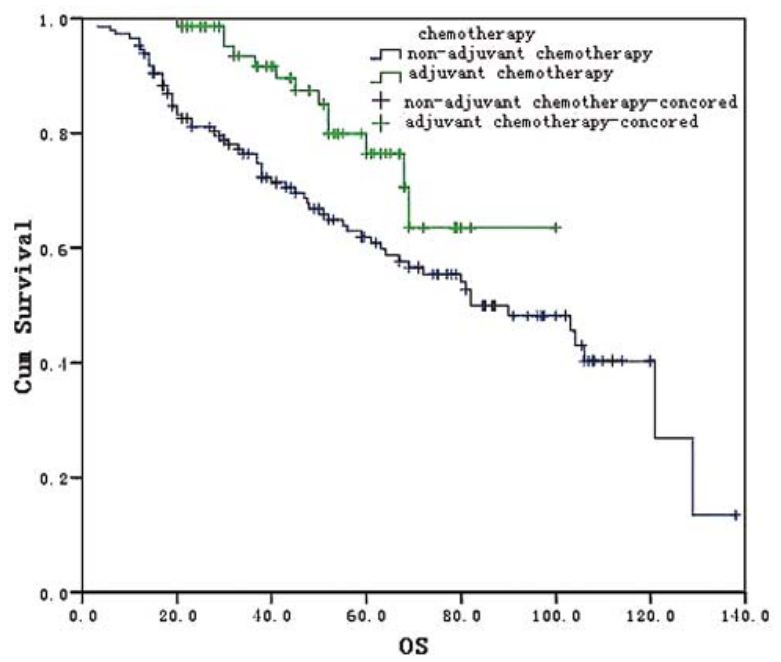

FIGURE 3. Survival curves for 220 patients undergoing laparoscopic or open radical resection in different age periods: $A$ : less than 60 years old; $B, 60-75$ years old; $C=A+B ; D, 75$ years old.

tion, differentiation, vascular thrombus, nerve invasion, lymph nodes revealed by postoperative pathology, or postoperative chemotherapy between the laparoscopic and open radical resection groups $(P>0.05)$ (Table 1$)$.

Twenty-nine patients were lost to the follow up with a loss rate of $11.6 \%$. The follow up period ranged from 3 to 128 months with an average of 52.5 months. There was no statistically significant difference in the 3-year survival $(88.5 \%$ vs. $80.5 \%$; $\left.X^{2}=1.98, P=0.159\right)$ and the 5-year survival $(81.9 \%$ vs. $69.2 \% ; X^{2}=1.98, P=0.159$ ) between both groups. However, statistically significant difference was found in mOS, which was 102.6 (95\% CI: 76.8-122.7) months in the laparoscopic group and 90.0 (95\% CI: 70.4-109.6) months in the open radical resection group $\left(X^{2}=4.183, P=0.041\right)$ (Figure 1). $\mathrm{mOS}$ was 96 (95\% CI: 68.6-111.4) months and 92.6 (95\% CI: 56.8107.2) months in those with or without postoperative chemotherapy, respectively $\left(X^{2}=6.389, P=0.011\right)$ (Figure 2).

For patients below 75 years old, the mOS was 108 (95\% CI: 68.9 173.0) months and 120.8 (95\% CI: 69.5 172.5)90.0 months in the laparoscopic and open radical resection groups, without statistically significant difference $\left(X^{2}=1.0136 .191, P=0.314\right)$. For patients older than 75 years the mOS was 90.0 (95\% CI 25.3 - 105.0) months and 83.4 (95\% CI: 13.1 - 96.9) months in the laparoscopic and open group, respectively. The difference between these two groups was statistically significant $\left(X^{2}=6.191\right.$, $\mathrm{P}=0.013$ ) (Figure 3).
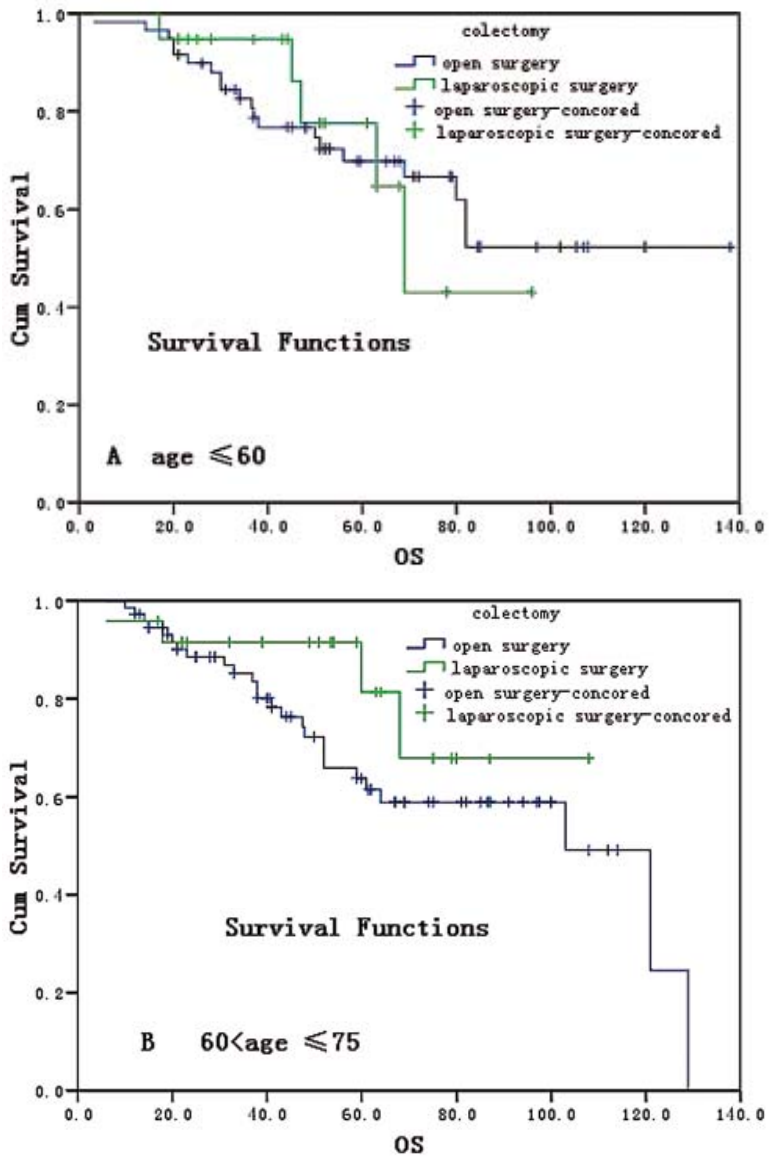

(A)
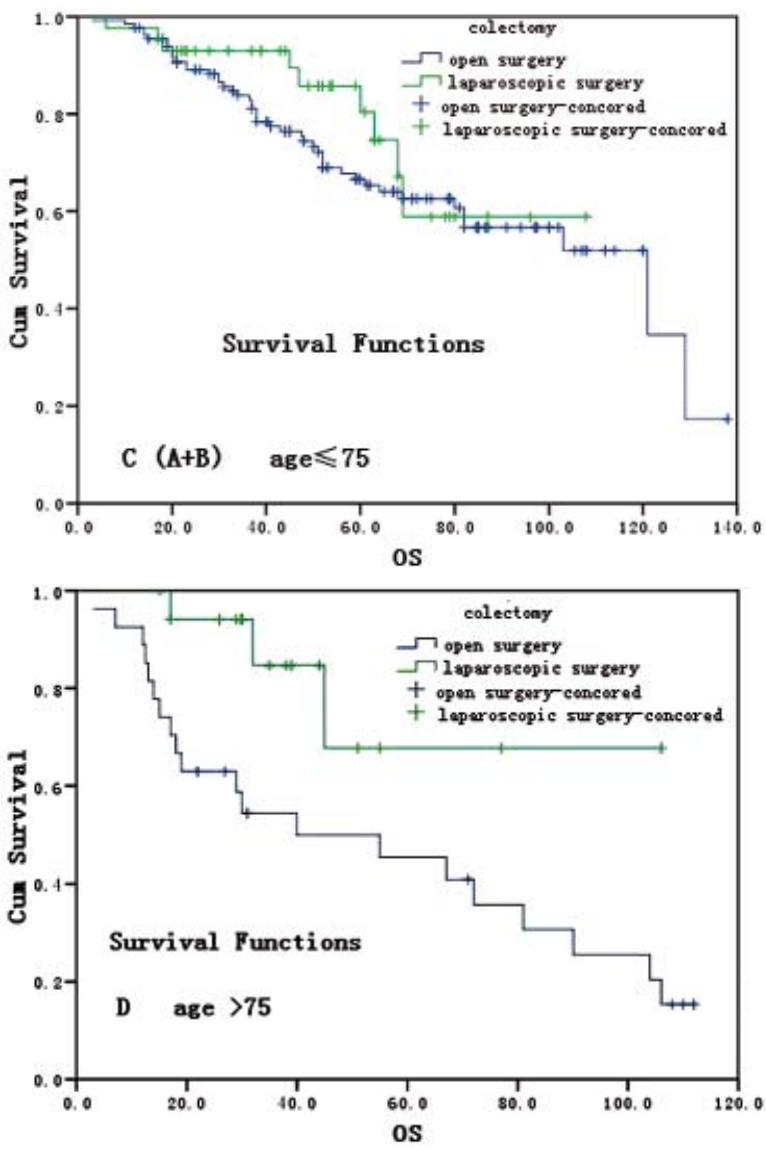

(D) 
TABLE 1. General information of 220 patients with stage II colon cancer

\begin{tabular}{|c|c|c|c|c|}
\hline & $\begin{array}{l}\text { Laparoscopic radical re- } \\
\text { section }\end{array}$ & $\begin{array}{l}\text { Open radical re- } \\
\text { section }\end{array}$ & $x^{2}$ & $\mathbf{P}$ \\
\hline Total & 61 & 159 & & \\
\hline $\begin{array}{l}\text { Sex } \\
\quad \text { Male } \\
\text { Female }\end{array}$ & $\begin{array}{l}28 \\
33\end{array}$ & $\begin{array}{l}86 \\
73\end{array}$ & 1.183 & 0.276 \\
\hline $\begin{array}{l}\text { Age } \\
\begin{array}{l}\sim 60 \text { years } \\
\sim 75 \text { years } \\
>75 \text { years }\end{array}\end{array}$ & $\begin{array}{l}19 \\
24 \\
18\end{array}$ & $\begin{array}{l}59 \\
73 \\
27\end{array}$ & 4.255 & 0.119 \\
\hline $\begin{array}{l}\text { Tumor site } \\
\text { Ascending colon } \\
\text { Transverse colon } \\
\text { Descending colon } \\
\text { Sigmoid colon }\end{array}$ & $\begin{array}{l}20 \\
6 \\
10 \\
25\end{array}$ & $\begin{array}{l}75 \\
14 \\
22 \\
48\end{array}$ & 3.910 & 0.418 \\
\hline $\begin{array}{l}\text { Pathological classification } \\
\text { Highly differentiated } \\
\text { adenocarcinoma } \\
\text { Moderately differentiated } \\
\text { adenocarcinoma } \\
\text { Mucous adenocarcinoma } \\
\text { Lowly differentiated } \\
\text { adenocarcinoma with signet ring cells }\end{array}$ & $\begin{array}{l}1 \\
50 \\
6 \\
4\end{array}$ & $\begin{array}{l}4 \\
123 \\
20 \\
12\end{array}$ & 0.608 & 0.962 \\
\hline $\begin{array}{l}\text { Chemotherapy } \\
\text { Yes } \\
\text { No }\end{array}$ & $\begin{array}{l}23 \\
38\end{array}$ & $\begin{array}{l}41 \\
118\end{array}$ & 2.485 & 0.115 \\
\hline $\begin{array}{l}\text { Vascular thrombus } \\
\text { Yes } \\
\text { No }\end{array}$ & $\begin{array}{l}54 \\
7\end{array}$ & $\begin{array}{l}145 \\
14\end{array}$ & 0.364 & 0.546 \\
\hline $\begin{array}{l}\text { Nerve invasion } \\
\text { Yes } \\
\text { No }\end{array}$ & $\begin{array}{l}54 \\
6\end{array}$ & $\begin{array}{l}146 \\
13\end{array}$ & 0.1829 & 0.669 \\
\hline $\begin{array}{l}\text { Lymph node metastasis } \\
\quad \geq 12 \\
\quad<12\end{array}$ & $\begin{array}{l}24 \\
37\end{array}$ & $\begin{array}{l}90 \\
69\end{array}$ & 1.418 & 0.492 \\
\hline
\end{tabular}

\section{Discussion}

Since Jacobs et al. reported the initial use of laparoscopic radical resection of sigmoid colon, laparoscopic radical resection has been increasingly used for colorectal cancer. ${ }^{10}$ However, questions are raised regarding whether the long-term outcomes of laparoscopic radical resection are comparative to that of open radical resection and whether it leads to tumour metastasis.

This study showed that the 3-year survival was $88.5 \%$ and $80.5 \%$ in the laparoscopic and open radical resection groups in 220 patients with stage II colon cancer. Bonjer et al. ${ }^{6}$ reported that the 3 -year survival was $82.2 \%$ and $83.5 \%$ respectively for both groups in stage II colon cancer. Kitano et al..$^{11}$ found that the 5-year survival was $94.8 \%$ for laparoscopic radical resection, comparable to open radical resection. Fleshman et al. ${ }^{7}$ reported that the 5-year survival was $74.6 \%$ and $76.4 \%$ respectively for laparoscopic and open radical resection group in a multicentre study in 872 patients with colon cancer and concluded that there was no statistically significant difference in the overall survival and the diseasefree survival between two groups, suggesting that the long-term efficacy is similar for two procedures. This current study found similar results in stage II colon cancer patients, again confirming that laparoscopic radical resection can achieve favourable outcomes for early-stage colon cancer.

In our study the mOS was 102.6 months and 90.0 months in the laparoscopic and open radical resection groups with a statistically significant difference, further demonstrating laparoscopic radical resection has better survival outcomes than open radical resection. Bilimoria et al. ${ }^{12}$ reported that the 5-year survival was apparently better for laparoscopic radical resection in patients with stages I and II colon cancer. Lacy et al. ${ }^{9}$ revealed that laparoscopic radical resection reduced cancer recurrence, risks of mortality from cancer, and other risks, and that the tumour-bearing survival was better for laparoscopic radical resection than open radical resection in a long-term follow up of 218 cases of colon cancer. These results may be attributable to minimal invasion of the surgery and rapid rehabilitation of immune function following laparoscopic radical resection. ${ }^{13-15}$

The 5 -year survival is $75 \%-80 \%$ for stage II colon cancer following radical resection and $20 \%-25 \%$ pa- 
tients die of recurrence or distant metastasis. ${ }^{16}$ As there are no large-scale clinical trials that conclude that stage II colon cancer patients can benefit from postoperative adjuvant chemotherapy, postoperative chemotherapy is thus controversial for stage II colon cancer. ${ }^{17,18}$ The National Surgical Adjuvant Breast and Bowel Project (NSABP) thought that stage II colon cancer patients could benefit from adjuvant chemotherapy as stage III patients. ${ }^{19}$ In this study, the mOS was 96 months for patients with postoperative chemotherapy and 92.6 months for those without chemotherapy with a statistically significant difference, showing that chemotherapy is advantageous whatever surgical technique is adopted.

Although meta-analyses could not substitute large randomised clinical studies ${ }^{20}$, we cannot neglected that a pooled analysis of five randomized trials did not show the radical resection with adjuvant chemotherapy was better than radical resection alone. ${ }^{21}$ Therefore, the National Comprehensive Cancer Network (NCCN) guidelines recommend adjuvant chemotherapy for stage II colorectal cancer patients with risks for poor prognosis (high risks), such as poor histological differentiation, stage T4, invasion to blood vessels or lymph vessels, intestinal obstruction or perforation, tumours too near resection margins, and less than 12 lymph nodes for pathology examination. ${ }^{22}$ Moreover, some proteins are accepted as predictors for adjuvant chemotherapy for high-risk stage II colorectal cancer. ${ }^{23}$ Though this study indicates that chemotherapy was beneficial for patients like in the metastatic diseasse ${ }^{24}$, multi-centre trials with a large sample size and different chemotherapy regimens are required to demonstrate the effect of adjuvant chemotherapy for stage II colon cancer. Additionally, there was no statistically significant difference in the cancer site, histological classification, nerve invasion, lymph nodes, or postoperative chemotherapy between the laparoscopic and open radical resection groups.

About 50\% colorectal cancer patients are over 70 years old and colorectal cancer thus becomes a common disease for patients over 70 years old. ${ }^{25}$ According to the Colorectal Cancer Collaborative Group in UK, the risk of surgery for the old increases with age; the mortality was $1.3 \%-5.2 \%$ for patients of 65 years old or above, and $7.1 \%-8.9 \%$ for patients of 85 years or above. ${ }^{26}$ But another study demonstrates that radical resection is safe in old patients with colorectal cancer and high risks of radical resection are mainly correlated with complications and emergency treatment instead of age. ${ }^{27}$ In this study, there were 18 patients over 75 years old in the laparoscopic radical resection group and 27 patients over 75 years old in the open radical resection group. For patients of over 75 years old, it is suggested that the survival of laparoscopic radical resection is superior over open radical resection for stage II colon cancer. The advantage in survival is probably related to less invasive nature of laparoscopic procedure, which can be of greatest benefit in the patients older than 75 years

\section{Conclusions}

The survival of patients receiving laparoscopic radical resection was better than that of open radical resection for stage II colon cancer, especially for patients over 75 years old. Thus laparoscopic radical resection should be selected for these stage II colon cancer patients as well as postoperative adjuvant chemotherapy for better survival.

\section{References}

1. Center MM, Jemal A, Smith RA, Ward E. Worldwide variations in colorectal cancer. CA Cancer J Clin 2009; 59: 366-8.

2. Hendon SE,DiPalma JA. U.S. practices for colon cancer screening. Keio J Med 2005; 54: 179-83.

3. Horvat M, Stabuc B. Microsatellite instability in colorectal cancer. Radiol Oncol 2011; 45: 75-81.

4. Hewett PJ, Allardyce RA, Bagshaw PF, Frampton CM, Frizelle FA, Rieger NA et al. Short-term outcomes of the Australasian randomized clinical study comparing laparoscopic and conventional open surgical treatments for colon cancer: the ALCCaS trial. Ann Surg 2008; 248: 728-38.

5. Bonjer HJ, Hop WC, Nelson H, Sargent DJ, Lacy AM, Castells A, et al. Laparoscopically assisted vs open colectomy for colon cancer: a metaanalysis. Arch Surg 2007; 142: 298-303.

6. Buunen M, Veldkamp R, Hop WC, Kuhry E, Jeekel J, Haglind E, et al. Survival after laparoscopic surgery versus open surgery for colon cancer: long-term outcome of a randomised clinical trial. Lancet Oncol 2009; 10: 44-52.

7. Fleshman J, Sargent DJ, Green E, Anvari M, Stryker SJ, Beart RW Jr, et al. Laparoscopic colectomy for cancer is not inferior to open surgery based on 5-year data from the COST Study Group trial. Ann Surg 2007; 246: 655-62.

8. Velenik V. Post-treatment surveillance in colorectal cancer. Radiol Oncol 2010; 44: 135-141.

9. Lacy AM, Delgado S, Castells A, Prins HA, Arroyo V, Ibarzabal A, et al. The long-term results of a randomized clinical trial of laparoscopy-assisted versus open surgery for colon cancer. Ann Surg 2008; 248: 1-7.

10. Jacobs M, Verdeja JC, Goldstein HS. Minimally invasive colon resection (laparoscopic colectomy). Surg Laparosc Endosc 1991; 1: 144-50.

11. Kitano S, Kitajima M, Konishi F, Kondo H, Satomi S, Shimizu N; Japanese Laparoscopic Surgery Study Group. A multicenter study on laparoscopic surgery for colorectal cancer in Japan. Surg Endosc 2006; 20: 1348-52.

12. Bilimoria KY, Bentrem DJ, Nelson H, Stryker SJ, Stewart AK, Soper NJ, et al. Use and outcomes of laparoscopic-assisted colectomy for cancer in the United States. Arch Surg 2008; 143: 832-9. 
13. Milsom JW, Jerby BL, Kessler H, Hale JC, Herts BR, O'Malley CM. Prospective, blinded comparison of laparoscopic ultrasonography vs. Contrast-enhanced computerized tomography for liver assessments undergoing colorectal carcinoma asurgery. Dis Colon Rectum 2000; 43: 44-9.

14. Tang CL, Eu KW, Tai BC, Soh JG, MacHin D, Seow-Choen F. Randomized clinical trial of the effect of open versus laparoscopically assisted colectomy on systemic immunity in patients with colorectal cancer. Br J Surg 2001; 88: 801-7.

15. O'Connell J, Maggard M, Ko C. Colon cancer survival rates with the new American Joint Committee On Cancer sixth edition staging. I Nat/ Cancer Inst 2004; 96: 1420-5.

16. Braga M, Vignali A, Zuliani W, Radaelli G, Gianotti L, Martani C, et al. Metabolic and functional results after laparoscopic colorectal surgery: a randomized, controlled trial. Dis Colon Rectum 2002; 45: 1070-7.

17. Ota D, Nelson $\mathrm{H}$. The surgeon and adjuvant therapy for stage colon cancer. Anna Surg Oncol 2007; 14: 272-3.

18. Brain MW, Jeffreg AM, Harvey JM, Robert JM. Adjuvant treatment of colorectal cancer. CA Cancer J Clin 2007; 57: 168-85.

19. Mamounas E, Wieand S, Wolmark N, Bear HD, Atkins JN, Song K, et al. Comparative efficacy of adjuvant chemotherapy in patients with Dukes'B versus Dukes' $\mathrm{C}$ colon cancer: results form fournational surgical adjuvant breast and bowel project adjuvant studies(C-01, C-02, C-03, and C-04). J Clin Oncol 1999; 17: 1349-55.

20. Kovač V, Smrdel U. Meta-analyses of clinical trials in patients with non-small cell lung cancer. Neoplasma 2004; 51: 334-40.

21. Efficacy of adjuvant fluorouracil and folinic acid in B2 colon cancer. International Multicentre Pooled Analysis of B2 Colon Cancer Trials (IMPACT B2) Investigators. J Clin Oncol 1999; 17: 1356-63.

22. Benson AB 3rd, Schrag D, Somerfield MR, Cohen AM, Figueredo AT, Flynn PJ, et al. American Society of Clinical Oncology recommendations on adjuvant chemotherapy for stage II colon cancer. J Clin Oncol 2004; 22: 3408-19.

23. Strzelczyk B, Szulc A, Rzepko R, Kitowska A, Skokowski J, Szutowicz A, et al. Identification of high-risk stage colorectal tumors by combined analysis of the NDRG1 gene expression and the depth of tumor invasion. Ann Surg Oncol 2009; 16: 1287-94.

24. Ocvirk J. Advances in the treatment of metastatic colorectal carcinoma. Radiol Oncol 2009; 43: 1-8.

25. Parkin DM, Bray F, Ferlay J, Pisani P. Global cancer statistics, 2002. CA Cancer J Clin 2005; 55: 74-108.

26. Colorectal Cancer Collaborative Group. Surgery for colorectal cancer in the elderly: a systematic review. Lancet 2000; 16: 968-74.

27. Kruschewski M, Germer CT, Rieger H, Buhr HJ. Radical resection of colorectal carcinoma in the oldest old. Chirurg 2002; 73: 241-4. 